\title{
Variability in foraging behaviour of chick-rearing macaroni penguins Eudyptes chrysolophus and its relation to diet
}

\author{
B. E. Deagle ${ }^{1,2, *}$, N. J. Gales ${ }^{1}$, M. A. Hindell ${ }^{2}$ \\ ${ }^{1}$ Australian Antarctic Division, Channel Highway, Kingston, Tasmania 7050, Australia \\ ${ }^{2}$ School of Zoology, University of Tasmania, Box 252-05, Hobart, Tasmania 7000, Australia
}

\begin{abstract}
Flexibility in foraging behaviour and diet are characteristics of many penguin species. While these 2 aspects of foraging ecology are presumably tightly coupled, the connection between them is rarely examined directly. Using time-depth recorders and satellite telemetry we documented the foraging behaviour of 43 chick-rearing macaroni penguins Eudyptes chrysolophus at Heard Island. We also compared these behavioural data with prey recovered from the stomach contents of each tracked bird. During guard stage, foraging trips were significantly shorter (average duration = $23 \pm 18 \mathrm{~h}$, range $=47 \pm 40 \mathrm{~km}$ ) compared to crèche stage (average duration $=115 \pm 112 \mathrm{~h}$, range $=$ $169 \pm 102 \mathrm{~km}$ ). Crèche stage trips also included significantly more shallow dives that appear to be related to travel ( $39 \%$ of dives $<10$ m versus $27 \%$ for guard stage). Three species dominate the birds' diet: 2 species of euphausiids and the myctophid fish Krefftichthys anderssoni. Over the breeding season, $K$. anderssoni was taken on trips further from the island with deeper dives compared to the euphausiids. Foraging characteristics also differed between trips targeting different euphausiid prey species; however, there was a temporal shift in the euphausiid species consumed and this was correlated with overall changes in foraging behaviour. Multivariate analysis of behavioural data from trips early in guard stage revealed 2 distinct foraging strategies: deeper and offshore versus shallower and inshore. Individual birds often switched between these strategies in successive trips. The characteristics of many dives performed during inshore trips were indicative of benthic foraging; a previously unrecorded behaviour for macaroni penguins. Euphausiids were captured on both offshore pelagic and inshore benthic trips, illustrating that when prey is found in different habitats substantial changes in foraging parameters can occur independent of dietary shifts. More detailed behavioural studies may allow prey-specific rather than habitat-specific foraging patterns to be distinguished.
\end{abstract}

KEY WORDS: Dive behaviour · Prey-specific foraging · Time-depth recorder · Heard Island Feeding ecology $\cdot$ Benthic foraging

\section{INTRODUCTION}

Studies of foraging behaviour play a key role in our understanding of species ecology, evolution and conservation. In marine predators, the development and miniaturisation of animal-borne time-depth recorders (TDRs) and satellite telemetry devices has allowed increasingly detailed studies of diving behaviour and at-sea spatial usage (Wilson et al. 2002). Intraspecific temporal and spatial variability of foraging behaviour is common. Studies on penguins have documented substantial changes in foraging behaviour within species from different locations (e.g. Tremblay \& Cherel 2003, Lescroël \& Bost 2005) and during different phases of the annual cycle (e.g. Charrassin et al. 2002, Green et al. 2005, Clarke et al. 2006). Gentoo penguins Pygoscelis papua from adjacent colonies on the Kerguelen Archipelago show almost as much contrast in foraging behaviour as seen throughout the species' subantarctic range (Lescroël \& Bost 2005), 
and the foraging range of Adelie penguins $P$. adeliae can shift quite drastically over the relatively short chick-rearing period (Ainley et al. 1998, Clarke et al. 2006). Appreciation of this behavioural variability is important if results from individual studies are extrapolated to make wider conclusions about the species' ecology. This is especially true in situations where the behavioural information is used in the design of marine protected areas, or to assess interactions between predators and commercial fisheries (e.g. Boersma et al. 2002, Wienecke \& Robertson 2002).

One of the assumptions of many studies on the behavioural aspects of foraging is that changes in behaviour reflect differences in prey being targeted (Harcourt et al. 2002, Walker \& Boersma 2003, Green et al. 2005). In several studies on penguins, changes in foraging behaviour parameters of the populations do correlate with changes in diet (Green et al. 1998, Moore et al. 1999, Lescroël \& Bost 2005). However, relatively few studies combine behavioural and diet data from the same individual animals to test this linkage. One exception is a study by Ropert-Coudert et al. (2002) on Adelie penguins; in this study, only very minor changes in foraging patterns (swim speed during commuting phase of dive) were found between penguins that were capturing krill versus those that were primarily capturing fish. This finding illustrates the difficulty in establishing a direct link between these 2 aspects of foraging ecology, despite the fact that one would expect them to be highly correlated. It would be useful to further investigate whether preyspecific foraging behaviours can be discriminated in commonly measured behavioural parameters such as those recorded by TDRs, and whether changes in diet could explain the behavioural variability often observed. If prey-specific foraging patterns can be identified, it might be possible to predict the diet of birds based on behavioural records (Simeone \& Wilson 2003). This would be particularly helpful if it allowed inferences about the diet of birds outside the breeding season, or far offshore, when dietary information is difficult to obtain.

Macaroni penguins Eudyptes chrysolophus are the most numerous penguin species in the world and are the leading consumer of marine resources among seabirds, consuming an estimated 9.2 million tonnes of prey annually (Brooke 2004). The foraging locations and dive behaviour of these penguins have been studied during the breeding season at South Georgia (Croxall et al. 1993, Barlow \& Croxall 2002a, Barlow et al. 2002, Trathan et al. 2006) and Heard Island (Green et al. 1998, Trebilco 2004). In addition, dive data have been recorded over the entire annual cycle for some birds from South Georgia (Green et al. 2005). The diet of the species has been examined during the breeding season at several colonies and is usually dominated by euphausiids, but fish and other crustaceans can dominate the diet in some years or at some times of the annual cycle (Croxall \& Prince 1980, Brown \& Klages 1987, Klages et al. 1989, Green et al. 1998, Barlow et al. 2002, Crawford et al. 2003, Deagle et al. 2007, Cherel et al. 2007). No studies on macaroni penguins have related the diet of individual birds to their foraging behaviour.

Here we report the foraging location, dive behaviour and diet of macaroni penguins sampled over the 20032004 chick-rearing period at a colony on Heard Island. The study encompassed the 2 phases of chick-rearing: guard stage, when the female provisions the young chick while the male remains at the colony to brood/ guard (late December to mid-January); and crèche stage, where both sexes forage concurrently to provision the chick (mid-January to mid-February) (Barlow \& Croxall 2002b). The specific aims of this study were to (1) document foraging behaviour during chickrearing and compare the strategies adopted during guard and crèche stages; $(2)$ examine the link between diet and foraging parameters during chick-rearing; and (3) examine the variability in foraging behaviour and its relation to diet on a fine scale over a short period at the start of guard stage.

\section{MATERIALS AND METHODS}

Field site and study animals. Breeding macaroni penguins were studied at the Capsize Beach colony on the south-eastern coast of Heard Island $\left(53^{\circ} 05^{\prime} \mathrm{S}\right.$, $73^{\circ} 30^{\prime} \mathrm{E}$ ). Approximately 50000 pairs of macaroni penguins breed at this colony, with over a million pairs breeding at other nearby sites on the island (Woehler 2006). Data were collected between 2 December 2003 and 3 February 2004. Foraging trips completed before 15 January were classified as guard stage trips and those completed later were classified as crèche stage trips. A detailed comparison of diet and foraging parameters was carried out on 25 birds with foraging trips in a 10 day window at the start of guard stage (herein referred to as early guard birds). This analysis focused on the early guard birds for practical reasons: (1) to minimise confounding effects such as temporal changes in prey availability, seasonal differences in trip length, male-female differences in foraging behaviour and changing environmental conditions; (2) short foraging trips were made during this period and prey present in the stomach are likely to be representative of the prey captured over the entire trip. Each bird included in the study was sexed by bill measurement following Woehler (1995) and their breast feathers marked 
with dye to ensure individual birds were sampled only once.

Dietary analysis. The dietary data presented here are a subset of those considered in a previous study that examined stomach contents of 69 birds and obtained diet data through genetic analysis of faecal samples (Deagle et al. 2007). In the current study, only the stomach content data from birds equipped with data loggers $(n=43)$ are included, and the individual variation in diet composition is the focus rather than overall diet. Analysis methods have been presented in detail in Deagle et al. (2007). Stomach contents were obtained using the water-offloading technique (Wilson 1984) with a maximum of 2 flushes; recovered material was stored in $70 \%$ ethanol. In the laboratory, samples were drained on a $0.5 \mathrm{~mm}$ sieve, blotted dry and the total mass recorded. Sub-samples from each bird (30 g) were divided into broad prey categories under a dissecting microscope and the diet composition by mass was determined (Croxall et al. 1985). Only the prey groups that were present at $>5 \%$ by mass in at least one of the samples are considered here (euphausiids, fish and amphipods). Up to 100 amphipods and 100 euphausiids were identified per sample to determine species composition and recovered otoliths were used to identify the origin of the fish diet component.

Data loggers. Birds were fitted with a platform terminal satellite transmitter (PTT, Sirtrack) and a Mk 9 TDR (Wildlife Computers). Breeding birds were captured as they left the colony; instruments were attached to feathers in the midline of the lower back using cyanoacrylate glue (Loctite 401) and plastic cable ties (Trebilco 2004). The data loggers were streamlined in shape, and the smaller TDR $(39 \mathrm{~g} ; 87 \mathrm{~mm}$ long $\times 18 \mathrm{~mm}$ wide $\times 18 \mathrm{~mm}$ high) was positioned in front of the PTT (125 g; $138 \mathrm{~mm}$ long $\times 34 \mathrm{~mm}$ wide $\times 20 \mathrm{~mm}$ high) to reduce hydrodynamic drag. The combined mass of the data loggers were equivalent to $<5 \%$ of the average bird's body weight (Trebilco 2004). Birds were recaptured after between 1 and 6 foraging trips (median = 1 trip) and instruments recovered.

The PTTs transmitted every $45 \mathrm{~s}$ when dry and TDRs were programmed to sample pressure (depth) and temperature every $10 \mathrm{~s}$. The TDR sampling interval was longer than those in recent studies of this species (e.g. Green et al. 2005) and was the result of a programming error. This sampling interval limited our ability to examine some intra-dive variables (e.g. wiggles) and may have lead to an underestimation in the number of shallow dives performed (Wilson et al. 1995). During the second half of the study the TDRs were also inadvertently configured to store data only when wet. This had the effect of shortening average dive duration, as the units did not store data on time or pressure during inter-dive surface intervals. Conse- quently, the first reading in a dive was taken between 0 to $10 \mathrm{~s}$ from when the instrument was submerged and the final reading was taken 0 to $10 \mathrm{~s}$ before the instrument dried at the surface. We therefore only used dive duration data from the guard stage birds with TDRs that stored data continuously. The wet/dry sampling regime did not impact the ability to determine maximum dive depth as the zero depth reading could be determined with accuracy based on those dives with readings at the surface.

Data analysis. In most analyses, only behavioural data from the final foraging trip before collection of dietary samples were considered. The only exception was that overall foraging strategy was determined in successive excursions of the guard stage birds that carried instruments on multiple trips before being captured. Geographic locations were downloaded from the ARGOS satellite system and visualised using a purpose-written computer program, HeardMap (Frydman \& Gales 2007). All ARGOS location classes were imported into the program and maximum velocity of $15 \mathrm{~km} \mathrm{~h}^{-1}$ was used to filter the data (Frydman \& Gales 2007). Foraging tracks were plotted and range (direct distance between colony and furthest point on the filtered satellite track) of each foraging trip calculated using HeardMap. Dive records from the TDRs were visualised in Instrument Helper (version 1.0.0.5, Wildlife Computers) and the zero depth reading was set manually for all records. Dives (>3 m) were analysed in Instrument Helper and the following variables obtained for each dive: maximum dive depth, dive duration, bottom duration (time spent at $>90 \%$ of the maximum depth of the dive; see Charrassin et al. 2002) and ascent and descent rates (travel speed between surface and the depth at which bottom time commenced/ terminated).

Most analyses carried out used data expressed as a mean per foraging trip, ensuring that equal weighting was given to each bird. In the present study, as in a previous study on macaroni penguin dive behaviour (Green et al. 2005), there was a well-defined mode in the distribution of dive depths $<10 \mathrm{~m}$. We considered dives $<10 \mathrm{~m}$ to be primarily associated with travelling activities (referred to as shallow dives) and those $\geq 10 \mathrm{~m}$ were considered to be foraging dives (Green et al. 2005). Foraging trip characteristics considered for all birds include foraging trip range, foraging trip duration (calculated between the first and last dives $>3 \mathrm{~m}$ recorded from the TDR, validity confirmed with temperature data; Lescroël \& Bost 2005), total number of dives, mean maximum depth of dives, percentage of total dives that were classified as shallow dives and vertical travel distance per hour during daylight (VTD; calculation excluded activity during hours of darkness between 21:00 and 03:00 h). In early guard, additional 
dive characteristics examined included: mean dive duration, percentage of foraging dives in various depth bins (10-39 m, 40-69 $\mathrm{m}$ and >70 m), percentage of foraging trip daylight hours spent diving, mean bottom time and maximum depth attained during a foraging trip. To compare differences in foraging parameters between groups of penguins the data were ranked and an unequal variance $t$-test applied (Ruxton 2006). Multivariate significance tests of these data (e.g. ANOSIM) (Clarke \& Gorley 2001) were not performed since most parameters are correlated and p-values are dependent on the suite of parameters analysed.

To visualize time-depth dive patterns during chick rearing, perspective plots of $2 \mathrm{D}$ binned kernel density estimates (maximum dive depth versus time) were constructed in the statistical computing package $\mathrm{R}$ (www.r-project.org). To give an equal weighting to individual birds, the lowest number of dives recorded for a bird within a stage was determined (guard: $\mathrm{n}=$ 86; crèche: $\mathrm{n}=322$ ) and this number of dives was randomly sampled from all individuals in the group (Tremblay \& Cherel 2003).

Multivariate differentiation of the diet data and dive parameters were assessed using multi-dimensional scaling (MDS) and principal component analysis (PCA), respectively. MDS was used with the diet data since the data were highly skewed and zero-zero matches were common. The MDS ordination was based on the Bray-Curtis dissimilarity matrix calculated from proportions of prey groups in the stomach contents of all birds (100 restarts, 999 iterations each). PCA was used to characterise dive parameters obtained from the 25 early guard stage birds since these data were more normally distributed and not affected by joint absences; this allowed us to determine the contributions of variables to each principal component. PRIMER version 5 statistical software was used for all multivariate procedures (Clarke \& Gorley 2001).

\section{RESULTS}

TDR data and diet samples from the corresponding foraging trip were obtained from a total of 43 macaroni penguins over the chick-rearing period. This included 34 birds with foraging trips ending during guard stage and 9 birds with trips ending during crèche. PTT data were obtained from 30 of these guard stage birds and all of the crèche birds $(n=39)$. As expected, all of the penguins foraging during the guard stage were female (based on beak measurements), 3 of the crèche birds were males. A total of 31715 dives $>3 \mathrm{~m}$ were performed during the foraging trips proceeding collection of diet samples; of these dives 18869 were to depths $\geq 10 \mathrm{~m}$.

\section{Entire chick-rearing period}

Variation in diet. The mass of stomach contents recovered ranged from 16 to $205 \mathrm{~g}$ (mean $\pm \mathrm{SD} ; 71 \pm$ $47 \mathrm{~g}$ ). Four prey species accounted for more than $95 \%$ of the mass of prey in each of the stomach samples. These were 2 species of euphausiids (Euphausia vallentini and Thysanoessa macrura), a myctophid fish (Krefftichthys anderssoni) and an amphipod (Themisto gaudichaudii). For details on less common prey species see Deagle et al. (2007). Some individual birds captured exclusively E. vallentini, Thysanoessa macrura or $K$. anderssoni; however, the majority of birds captured a mixture of these 3 prey species. A single bird contained close to $100 \%$ Themisto gaudichaudii; this amphipod was uncommon in the rest of the samples. MDS based on diet dissimilarity suggests some general divisions among the birds in the current study. Four groups of birds can be identified in which one of the major prey species accounted for $>70 \%$ of the stomach contents (Fig. 1). Three additional groups were of birds that contained a more equally weighted mixture of diet items (Fig. 1).

Variation in foraging behaviour. As was previously reported for foraging trips in early guard stage (Trebilco 2004), there was a strong correlation between trip duration and trip range over the entire chick-rearing period (Spearman's rank: $r_{S}=0.97, p<0.001$ ). Both these parameters were also highly correlated to the

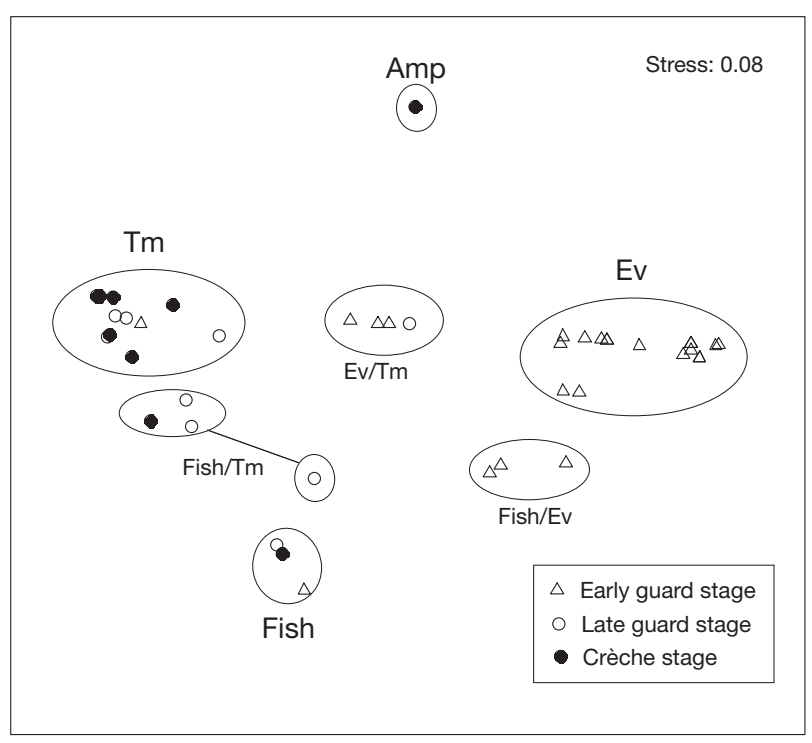

Fig. 1. Eudyptes chrysolophus. MDS ordination of Bray-Curtis dissimilarities calculated from proportions of major prey species in 43 stomach samples. Seven clusters separated by dissimilarity greater than 35\% (based on cluster analysis) are shown. Tm: euphausiid, Thysanoessa macrura; Ev: euphausiid, Euphausia vallentini; Amp: amphipod, Themisto gaudichaudii; Fish: myctophid, Krefftichthys andersoni 
number of dives performed $\left(\mathrm{r}_{\mathrm{S}}=0.98\right.$ and 0.97 respectively, $\mathrm{p}<0.001$ for both). There was a generally increasing trend in these variables (trip duration, trip range and number of dives) throughout the chick-rearing period and all were significantly different between guard and crèche stages (Table 1 ). Two crèche stage birds, both of them males, took exceptionally long trips (12 $\mathrm{d}$ each versus a maximum of $4 \mathrm{~d}$ in the other birds). Removing these 2 birds from the analysis (or all 3 males) did not change the statistical significance of differences in foraging trip characteristics between the stages (Table 1). All foraging activity occurred in a relatively narrow band to the southeast of Heard Island (Fig. 2).

Dives occurred at all times throughout the $24 \mathrm{~h}$ period; however, only $2 \%$ of the recorded foraging dives $(\geq 10 \mathrm{~m}$ ) occurred between 21:00 and 03:00 $\mathrm{h}$ local time, a $6 \mathrm{~h}$ interval corresponding to the period of lowest light level. Throughout chick-rearing there were minor peaks in dive activity around sunrise and sunset, with the deepest dives occurring at these times (Fig. 3). The most distinct difference in dive behaviour between stages was that crèche stage birds performed significantly more shallow dives (Table 1; Fig. 3). Guard birds had a peak in dive activity to depths between 5 and $20 \mathrm{~m}$ in the middle of the day (Fig. 3). There were no statistically significant differences in the mean maximum dive depths, or mean depth of foraging dives between stages (Table 1). The relative vertical travel distance per daylight hour also remained constant between stages.

Diet and foraging behaviour comparison. There was a change in the main euphausiid species consumed over the chick-rearing period (Fig. 1) and this was accompanied by changes in some foraging characteristics (e.g. foraging trip range; Fig. 4). This correlation makes the identification of foraging behaviours that are specific to the euphausiid species consumed difficult to discern. For example, Euphausia vallentini (a)

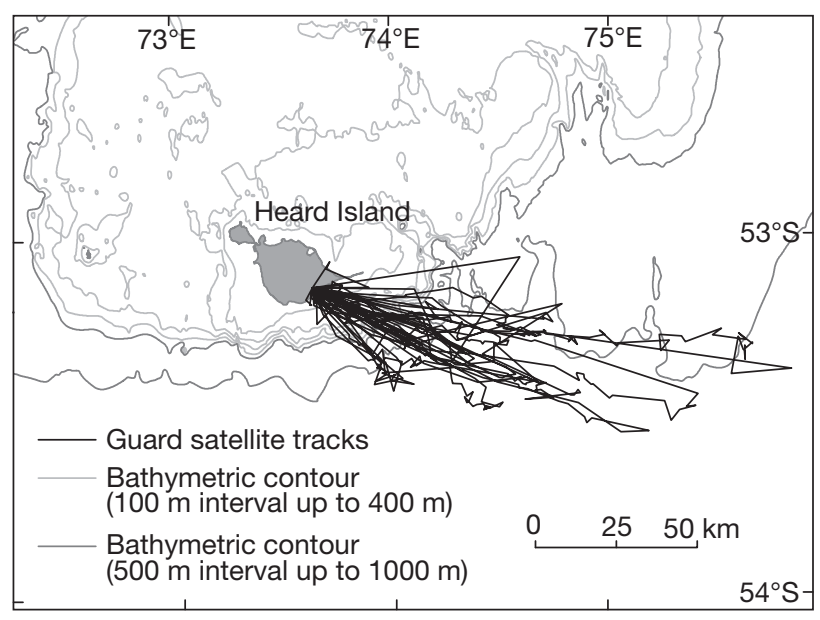

(b)

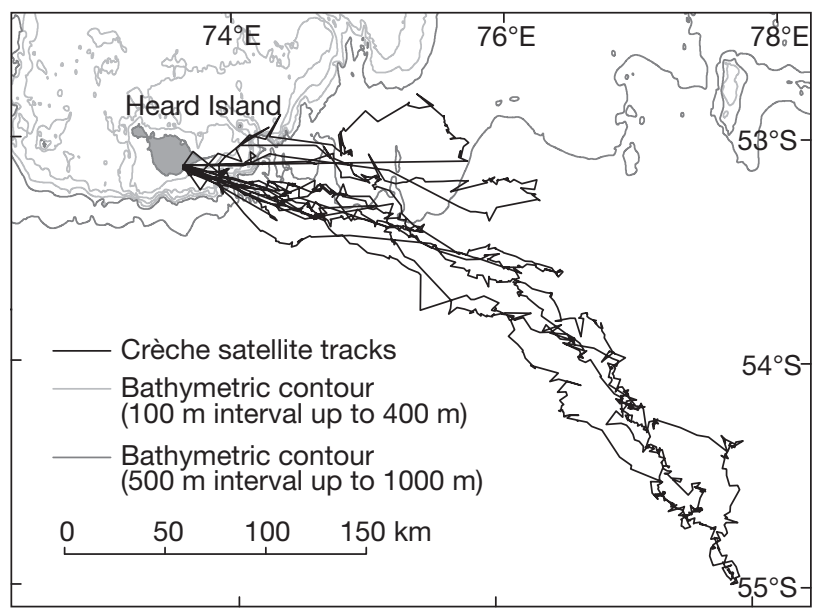

Fig. 2. Eudyptes chrysolophus. Inferred path of birds, based on satellite positions, in foraging trips prior to the collection of stomach content data. Trips carried out during (a) guard stage, (b) crèche stage. All data were collected during the 2003-2004 summer. Map projections: UTM zone 43

Table 1. Eudyptes chrysolophus. Foraging trip characteristics of macaroni penguins during the guard and crèche stages of chickrearing. Variables were compared using an unequal variance $t$-test performed on ranked data. Vertical travel distance calculation excluded activity during hours of darkness between 21:00 and 03:00 h. ${ }^{*}$ Significant difference between foraging parameter of guard and crèche stage $(\mathrm{p}<0.05$, bold $)$

\begin{tabular}{|c|c|c|c|c|c|c|c|c|c|c|c|}
\hline & \multicolumn{4}{|c|}{$\longrightarrow$ Guard $(\mathrm{n}=34)-$} & \multirow{2}{*}{$\overline{\text { Mean }}$} & \multicolumn{2}{|c|}{ Crèche $(\mathrm{n}=9)$} & \multirow{2}{*}{ Max. } & \multirow[b]{2}{*}{$t^{\prime}$} & \multirow{2}{*}{$\begin{array}{l}\text { Statistic } \\
\quad \mathrm{df}\end{array}$} & \multirow{2}{*}{ ics } \\
\hline & Mean & $\mathrm{SD}$ & Min. & Max. & & $\mathrm{SD}$ & Min. & & & & \\
\hline Foraging trip duration (h) & 23.0 & 17.9 & 3.9 & 77.6 & 114.7 & 111.8 & 25.1 & 311.2 & -6.00 & 20.7 & $<0.001^{*}$ \\
\hline Foraging trip range $(\mathrm{km})$ & 46.7 & 39.5 & 0.5 & 150 & 169.1 & 102.2 & 53 & 347 & -5.69 & 19.8 & $<0.001^{*}$ \\
\hline Number of dives & 435 & 321 & 86 & 1429 & 1880 & 1786 & 322 & 4948 & -4.22 & 14.6 & $<0.001^{*}$ \\
\hline Mean maximum dive depth $(\mathrm{m})$ & 26.4 & 8.6 & 11.5 & 42.0 & 29.2 & 10.3 & 19.3 & 54.1 & -0.52 & 14.5 & 0.610 \\
\hline Mean maximum depth foraging dives $(\geq 10 \mathrm{~m})$ & 36.1 & 13.0 & 13.2 & 55.2 & 45.5 & 8.4 & 36.2 & 58.8 & -1.97 & 14.3 & 0.068 \\
\hline$\%$ shallow dives $(<10 \mathrm{~m})$ & 27 & 13 & 4 & 51 & 39 & 16 & 8 & 59 & -2.33 & 12.1 & $0.038^{*}$ \\
\hline Vertical travel distance $\left(\mathrm{m} \mathrm{h}^{-1}\right)$ & 1205 & 289 & 509 & 1833 & 1205 & 365 & 701 & 1814 & 0.03 & 11.2 & 0.979 \\
\hline
\end{tabular}


(a) Guard dives

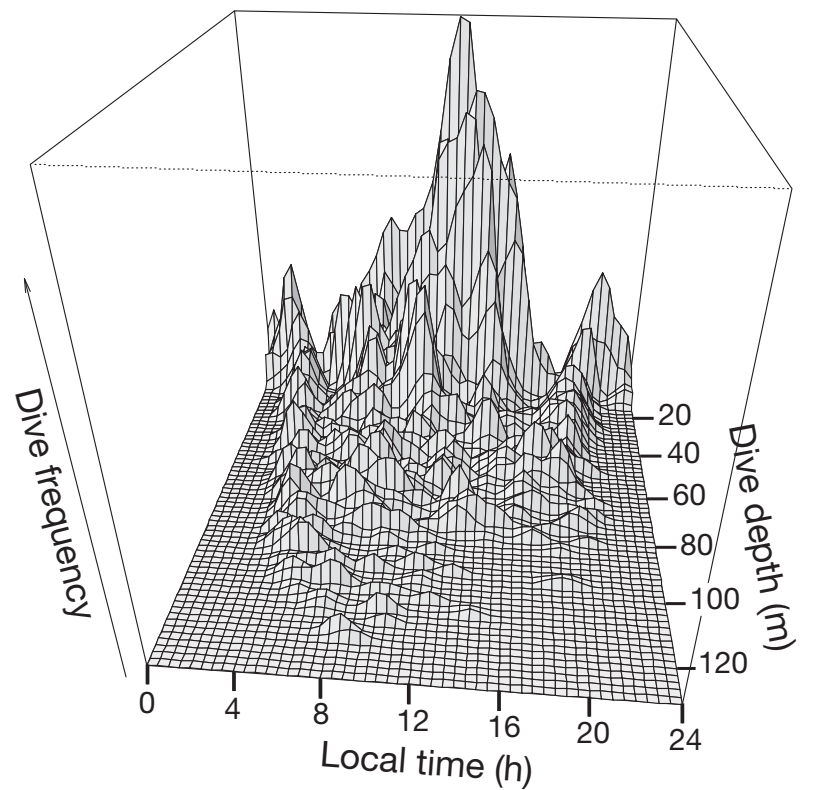

(b) Crèche dives

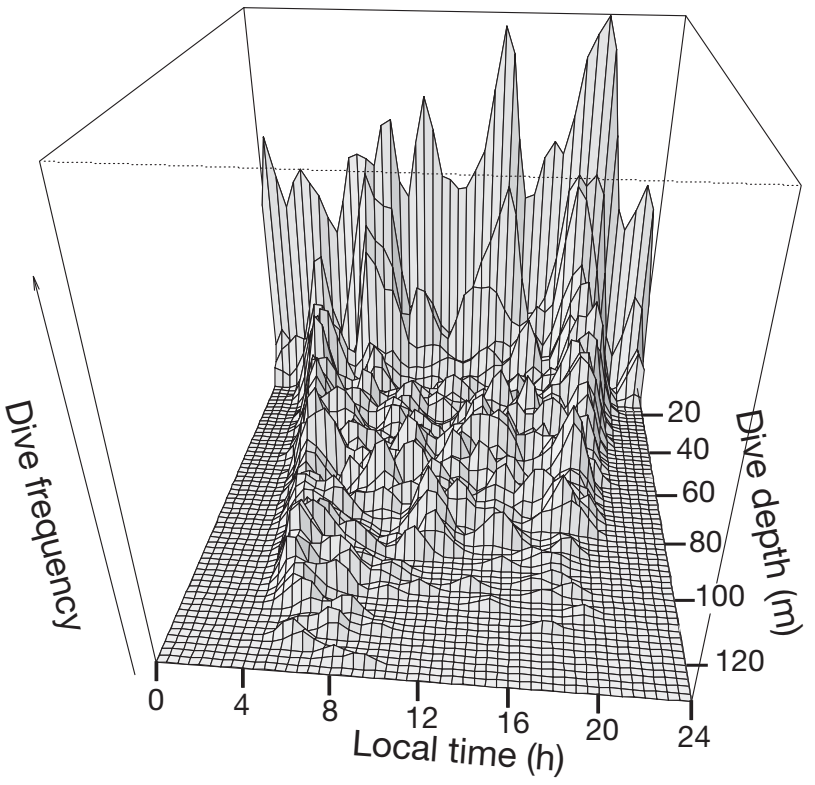

Fig. 3. Eudyptes chrysolophus. Distribution of maximum dive depths over a $24 \mathrm{~h}$ period in dives $>3 \mathrm{~m}$ for (a) 34 guard and (b) 9 crèche stage macaroni penguins. Data are shown as perspective plots of 2D binned kernel density estimates, an equal number of dives were randomly sampled from each penguin within a stage (results shown represent a total of 2924 dives from guard stage and 2898 from crèche stage)

tended to be taken on shorter trips with shallower dives compared to Thysanoessa macrura (Table 2). However, all birds that consumed primarily E. vallentini $(\mathrm{n}=17$ ) had foraging trips ending before 30 December. During this time all foraging trips were relatively short (Fig. 4) and dives tended to be shallower (see next section of 'Results'). Conversely, 9 out of 10 birds that consumed primarily $T$. macrura returned from foraging trips after 30 December. So, the foraging differences seen between birds eating different euphausiids could reflect actual differences in foraging tactics due to change in prey, or could be explained by temporal differences in foraging behaviour that are independent but coinciding with a shift in prey availability.

Fish were taken throughout the chick-rearing period by the tracked birds, allowing a more balanced appraisal of fish versus euphausiid-specific foraging behaviours. Birds with substantial amount of fish in their stomach (Fish, Fish/Ev, Fish/Tm individuals; Fig. 1) made up $24 \%$ of those sampled during guard stage and $22 \%$ of those

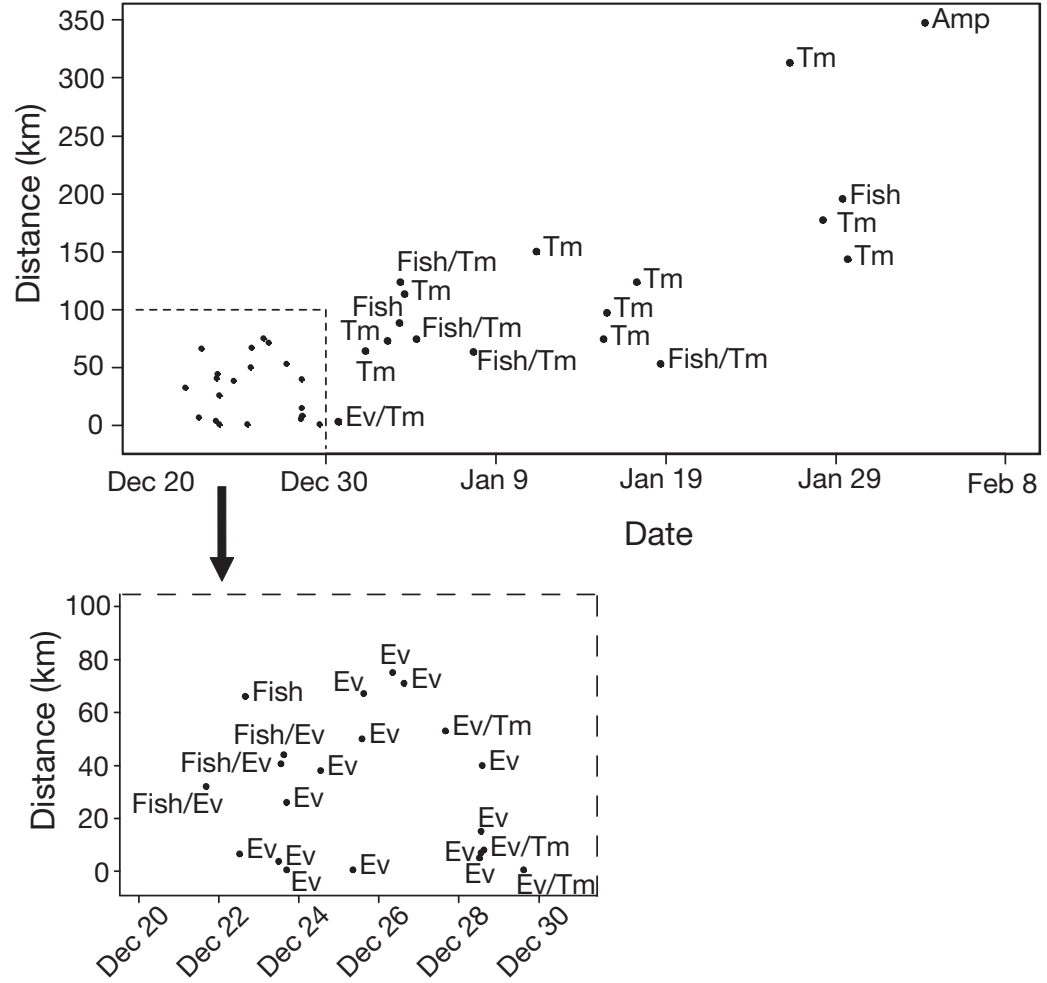

Fig. 4. Eudyptes chrysolophus. Foraging trip range in relation to date with dietary classification of individual penguins labelled on the plot. Abbreviations as defined in Fig. 1. Only data from penguins with functioning satellite transmitters are shown $(n=39)$ 


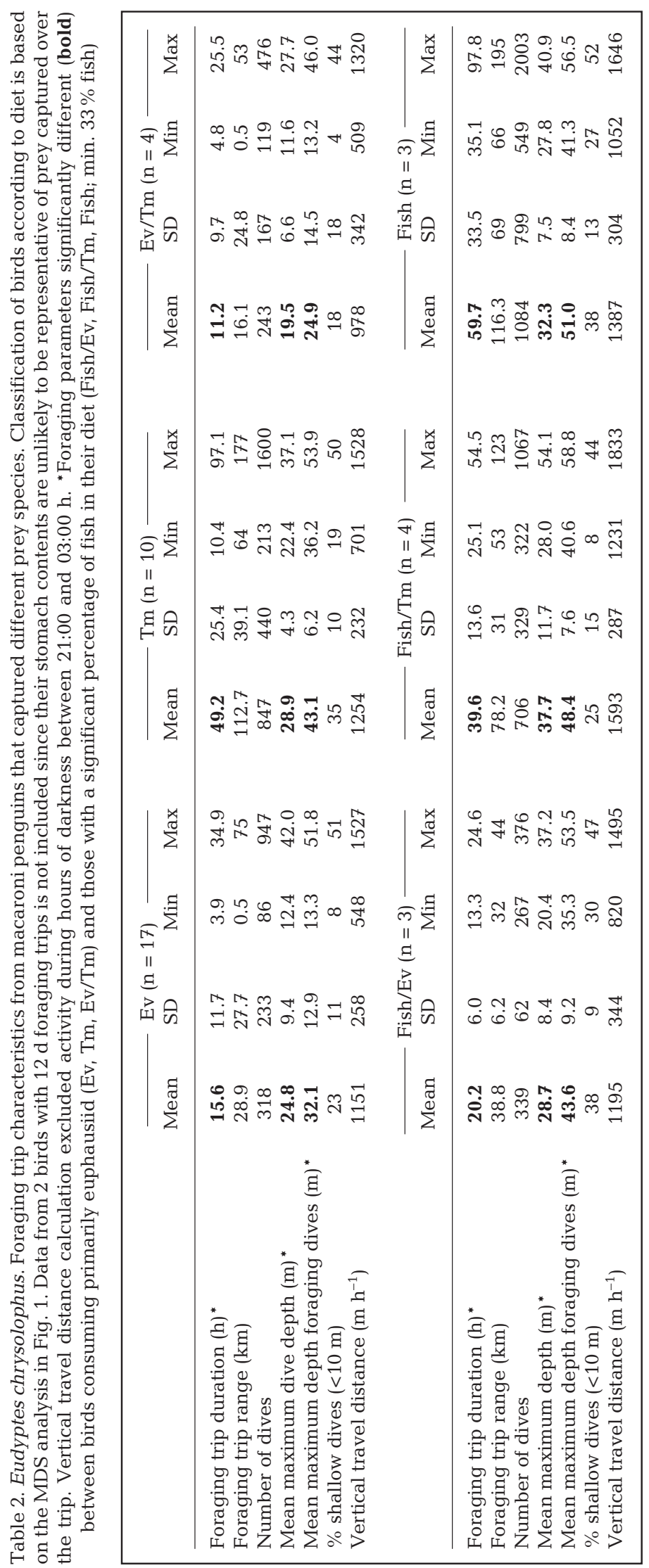

sampled during crèche stage. Comparisons of the foraging behaviours of these birds with those returning with primarily euphausiids (Ev, Tm and Ev/Tm individuals) reveal some significant differences in foraging parameters between the groups (Table 2). The birds that successfully foraged for fish dived deeper than those capturing euphausiids: mean maximum depths were $33.3 \pm 9.5 \mathrm{~m}$ versus $25.4 \pm 8.1 \mathrm{~m}\left(t^{\prime}=-2.55, \mathrm{df}=18.2, \mathrm{p}=0.012\right)$ and the mean maximum depth of foraging dives were $47.7 \pm 7.9 \mathrm{~m}$ versus $34.7 \pm 12.7 \mathrm{~m}\left(t^{\prime}=-3.11\right.$, $\mathrm{df}=17.3, \mathrm{p}=0.006)$. The trip duration was also significantly longer for birds returning with fish in their stomach: $39.8 \pm 24.1 \mathrm{~h}$ compared with $25.9 \pm$ $23.4 \mathrm{~h}$ for the krill consumers $(t=-2.44, \mathrm{df}=21.6$, $\mathrm{p}=0.023)$.

\section{Early guard stage diet and foraging strategies}

As would be expected from the general trends in diet over the chick-rearing period, the diet of early guard stage birds was dominated by Euphausia vallentini, but some birds had a significant proportion of Thysanoessa macrura and fish (Fig. 1). To investigate variability of foraging behaviours in these birds we carried out a PCA on a suite of foraging trip parameters (Table 3). PC1 accounted for $63 \%$ of the variation in the dive parameters, and PC2 only accounted for a further $17 \%$. Plots revealed clear separation of guard stage birds into 2 distinctive foraging groups on PC1 (Group A and Bi Fig. 5). PC1 had evenly spread loadings: positive values were obtained for mean bottom time and proportion of foraging dives between 10 and $39 \mathrm{~m}$; negative values were obtained for mean maximum depth, maximum dive depth, percent shallow dives, trip duration, proportion of foraging dives over $40 \mathrm{~m}$ and relative vertical travel distance per daylight hour (Table 3). The foraging strategies of these 2 groups were investigated further.

Group A birds made trips lasting an entire day or 2 days whereas Group B had short trips, generally occurring in the middle of the day (Table 3). Virtually all Group B birds were located within $5 \mathrm{~km}$ of the island inside the $100 \mathrm{~m}$ isobath. Group A birds had markedly shorter bottom times compared to Group B birds; this was not due to differences in dive durations but an increase in ascent and decent rates in Group B birds (Fig. 6). The increased dive transit rates and long bottom times are indicative of benthic dives (Tremblay \& Cherel 
Table 3. Eudyptes chrysolophus. Principal component axes from analysis of summary dive data for foraging trips from 25 guard stage macaroni penguins, and foraging characteristics (mean $\pm \mathrm{SD}$ ) of Groups A and B separated by PC1 (see Fig. 5). Percentage time diving and vertical travel distance calculation excluded activity during hours of darkness between 21:00 and 03:00 h. Percentage intra-depth zone (\% IDZ) dives not included as a variable in the principal component analysis (na: not applicable)

\begin{tabular}{|lrccc|}
\hline Variable & PC1 & PC2 & Group A & Group B \\
\hline Mean max. dive depth $(\mathrm{m})$ & -0.345 & 0.27 & $30.1 \pm 6.8$ & $17.3 \pm 4.8$ \\
Max. depth attained (m) & -0.363 & -0.024 & $95.6 \pm 10.6$ & $35.9 \pm 16.6$ \\
\% time diving & 0.115 & 0.276 & $61.3 \pm 9.6$ & $66.9 \pm 11.7$ \\
Mean dive duration (s) & -0.246 & 0.503 & $98.5 \pm 12.1$ & $89.2 \pm 6.6$ \\
Mean bottom time (s) & 0.290 & 0.384 & $24.5 \pm 4.9$ & $40.9 \pm 6.3$ \\
Trip duration (h) & -0.272 & -0.218 & $23.4 \pm 8.9$ & $6.1 \pm 1.8$ \\
\% shallow dives & -0.219 & -0.541 & $33.8 \pm 11.0$ & $15.1 \pm 5.8$ \\
\% dives 10-39 m & 0.367 & -0.010 & $49.9 \pm 14.8$ & $96.6 \pm 6.7$ \\
\% dives 40-69 m & -0.350 & 0.004 & $34.2 \pm 11.5$ & $3.4 \pm 6.7$ \\
\% dives 70+ m & -0.350 & 0.023 & $15.8 \pm 6.5$ & 0.0 \\
Vertical travel distance & -0.301 & 0.330 & $1271.8 \pm 188.6$ & $924.4 \pm 243.1$ \\
(m $\mathrm{h}^{-1}$ ) & na & na & $64.4 \pm 3.8$ & $84.0 \pm 5.0$ \\
\% IDZ dives & & & & \\
\hline
\end{tabular}

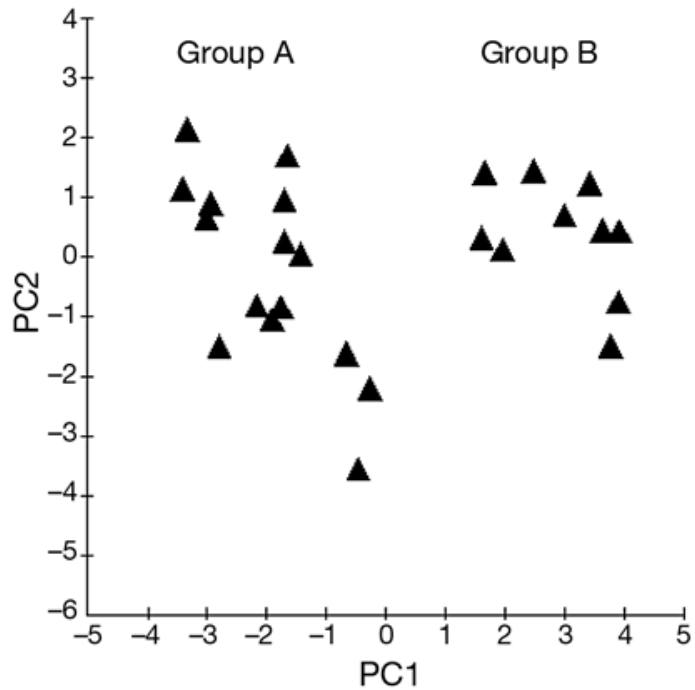

Fig. 5. Eudyptes chrysolophus. First 2 principal components (PC1 and PC2) obtained using 12 foraging trip dive parameters from 25 early guard stage penguins (see Table 3 for parameters and loadings). Two foraging groups identified by PC1 are labelled

2000). Benthic foraging is also characterized by series of dives to a narrow depth zone (i.e. the bottom) and foraging trips with a high proportion of benthic dives therefore have a higher percentage of intra-depth zone (IDZ) dives compared to non-benthic foraging trips. (Tremblay \& Cherel 2000, Takahashi et al. 2003). We calculated percentage of IDZ dives for early guard foraging trips, defining depth zone as depth $\pm 10 \%$ of the maximum depth reached by the preceding dive (Tremblay \& Cherel 2000). Group A birds had a lower per- cent of IDZ dives $(64.4 \pm 3.8 \%$; range $=$ $59.4-74.2 \%)$ than Group B birds (84.0 \pm $5.0 \%$; range $=77.4-90.8 \%$ ), again indicating that Group B birds are foraging benthically (Fig. 7).

The percentage of IDZ dives during a trip provides an indication of the overall foraging strategy (Table 3). We calculated this statistic for multiple trips from individual birds to examine whether individuals displayed consistent foraging tactics between early guard stage trips. These data were available from 10 penguins that were not captured on returning from their first (or second) foraging trip after instrument deployment. Penguins did not display a fidelity to a particular foraging strategy; there were 4 inter-trip changes between benthic and pelagic strategies out of 13 comparisons (Fig. 8). Visual inspection of dive profiles also revealed that some individuals utilised both strategies within individual trips (e.g. switch from pelagic to benthic dives at the end of trip; Fig. 7a).

To determine if differing foraging strategies were correlated with differences in prey captured by the birds, we plotted the foraging characteristics PC1 versus proportions of the 3 major prey species (Fig. 9). The plot reveals Group A birds consumed euphausiids and fish, whereas Group B birds fed solely on euphausiids. This indicates that both inshore benthic and offshore pelagic foraging strategies are used to target euphausiids, whereas fish are only being captured when these birds adopt the offshore pelagic foraging strategy.

\section{DISCUSSION}

This study provides detailed data on the variation in foraging location and dive depths used by macaroni penguins over the chick-rearing period at Heard Island. It is also the first study combining data on the foraging behaviour of individual macaroni penguins with detailed information on their diet. Our results show that the duration and range of foraging trips increases during chickrearing. This is probably due to a combination of changing constraints imposed by the requirements of offspring, and changes in the distribution of the most profitable prey resources. Our analysis of TDR data revealed that benthic dives were performed by some individuals, a foraging tactic not previously recorded in this species. In some cases variability in foraging behaviour did reflect differences in prey species targeted (e.g. myctophids were taken on trips further from the colony with deeper dives compared to euphausiids). However, in 

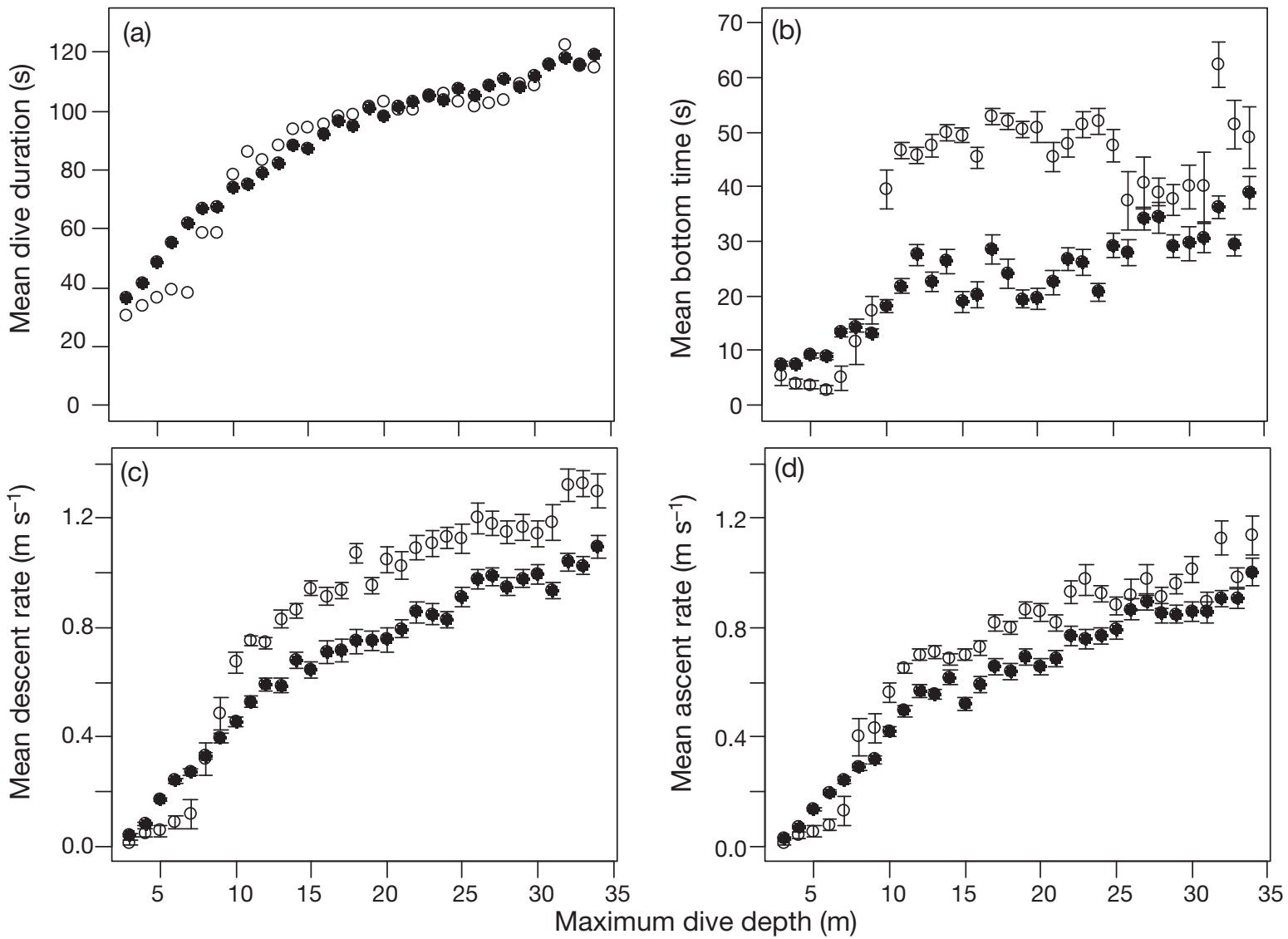

Fig. 6. Eudyptes chrysolophus. Dive parameters for m intervals (mean $\pm \mathrm{SE}$ ) in dives $<35 \mathrm{~m}$ for 2 groups of guard stage penguins identified in a principal component analysis (PCA) of summary dive data: (@) Group A, 4180 dives; (O) Group B, 1541 dives. See Fig. 5 and 'Results' for details of the PCA. (a) Dive duration, SE bars excluded for clarity; (b) bottom time; (c) descent rate; (d) ascent rate. Dives $>35 \mathrm{~m}$ were not included because there were too few data at these depths for Group B

other cases we observed changes in dive behaviour that did not reflect changes in prey consumption (e.g. Euphausia vallentini was the main prey taken in many nearshore benthic and offshore pelagic trips). Our analyses also illustrate the difficulties of comparing foraging data with diet data and we suggest some ways future studies could be improved.

\section{Instrument effects}

The attachment of external data loggers affects the diving performance of penguins (Ropert-Coudert et al. 2007) and the 2 loggers deployed simultaneously in the current study represent a considerable payload for a macaroni penguin. The impacts that these instruments had on foraging behaviour is difficult to assess since all our behavioural data came from birds carrying the same instruments, and trip length was not monitored in non-instrumented birds. One indication of foraging trip success is the mass of stomach contents recovered; in the current study this was $71 \pm$
$47 \mathrm{~g}$, considerably smaller than reported in some other diet studies on macaroni penguins at other locations (e.g. $273 \pm 141$ g; Brown \& Klages 1987), raising the possibility that our instruments had a major impact on foraging success. To examine this further we compared stomach content mass data from the current study with data from 8 non-instrumented birds collected during the same field season (data from Deagle et al. 2007). While we generally obtained smaller samples from instrumented birds, with the large variance between samples there was not a significant difference between the means $(71 \pm 47 \mathrm{~g}$ versus $103 \pm 66 \mathrm{~g} ; t$-test, $\mathrm{p}=0.220$ ). The mass of stomach contents we recovered were comparable to those reported in 2 previous diet studies on Heard Island from non-instrumented birds (67 $\pm 50 \mathrm{~g}$, Green et al. 1998; $95.5 \pm 65$ g, Klages et al. 1989). In addition, the diversity of prey captured by instrumented birds was similar to that reported for non-instrumented birds (Klages et al. 1989, Green et al. 1998). While we cannot discount the influence of instrument effects in the current study, the variety of prey successfully cap- 
(a) Guard Group A Penguin

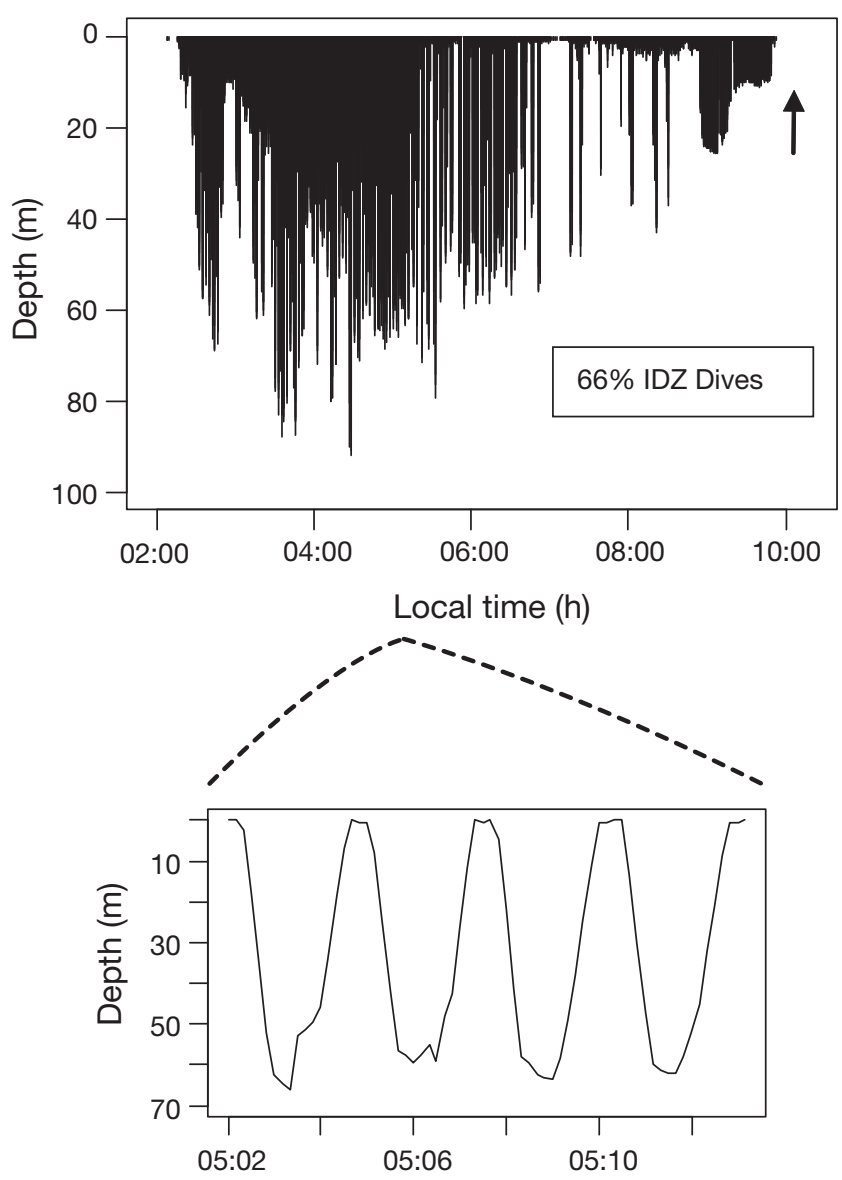

(b) Guard Group B Penguin
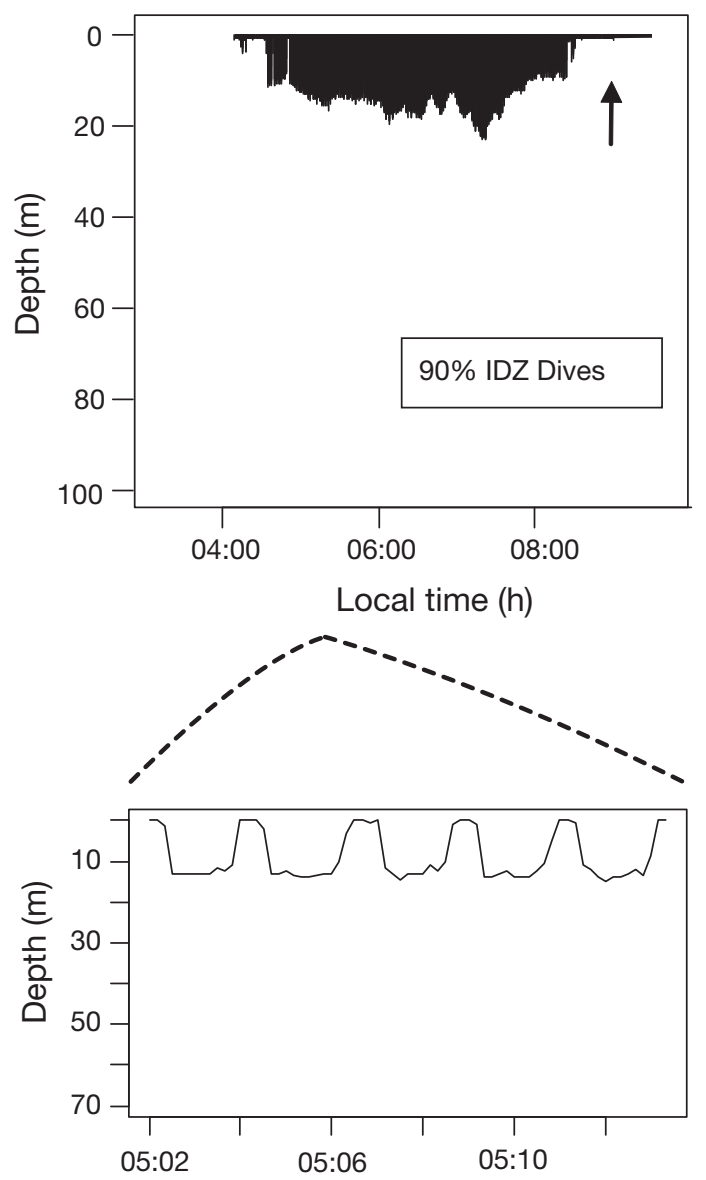

Fig. 7. Eudyptes chrysolophus. Diving profiles for 2 individual guard stage penguins on December 25, 2003. Records were selected to illustrate characteristic dive profiles of the 2 foraging groups (see 'Results' for details). Profile (a) shows only part of a foraging trip whereas (b) shows all dives recorded during a short foraging trip. Arrows: time when bird left the water (based on temperature data). The percentage of intra-depth zone (IDZ) dives is given for each trip. These penguins captured virtually identical prey (stomach content $90 \%$ by mass euphausiid Euphausia vallentini)

tured and wide variation in dive behaviour observed indicate it is possible to carry out comparative analyses between birds within this study.

\section{Foraging behaviour variation between guard and crèche stages}

The general foraging characteristics recorded at Heard Island over the chick-rearing period had many similarities with those documented at South Georgia, the location where the most detailed studies of macaroni penguin behaviour have been carried out. They include parameters such as foraging trip range (mean $74.9 \mathrm{~km}$, range $0.5-347 \mathrm{~km}$, this study; mean $62.1 \mathrm{~km}$, range $2.8-336 \mathrm{~km}$, Barlow \& Croxall 2002a), trip duration (median $25.1 \mathrm{~h}$, range $4-311 \mathrm{~h}$, this study; median $18.6 \mathrm{~h}$, range $0.5-358 \mathrm{~h}$, Barlow \& Croxall 2002a) and mean maximum depth of foraging dives $(38 \mathrm{~m}$, this study; $42 \mathrm{~m}$, Green et al. 2005). The uniformity of foraging trip trajectories for birds within a colony was consistent with the recent analysis carried out on guard stage birds at several colonies on South Georgia (Trathan et al. 2006). Our results did differ notably from studies carried out on macaroni penguins at South Georgia with regard to the change in foraging trip length between guard and crèche stages. At Heard Island, the duration and range of trips were shorter in guard stage compared to crèche stage. The opposite relationship, or no significant differences, in foraging trip durations between stages have been reported for birds from South Georgia (Barlow \& Croxall 2002a,b, Green et al. 2005). This may be partially due to the fact that our study included a disproportionate number of foraging trips in the early part of guard stage, since trip length increases during guard stage (Trebilco 2004). 


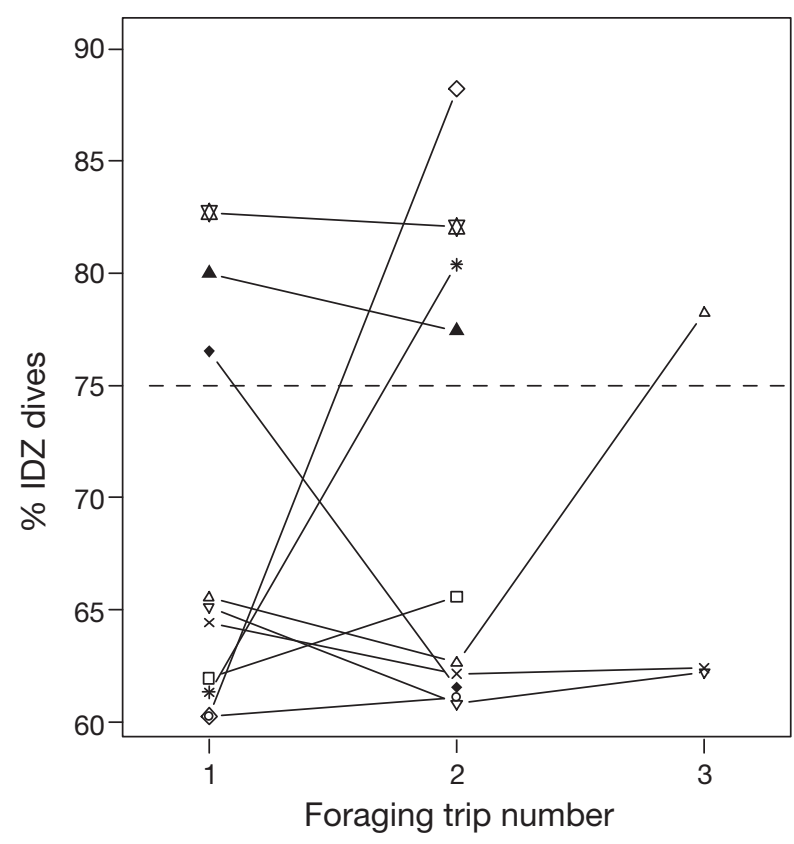

Fig. 8. Eudyptes chrysolophus. Percentage of intra-depth zone (IDZ) dives in successive foraging trips of 10 early guard stage penguins. Each individual is represented by a distinct symbol and successive trips are joined by a solid line. Dashed line divides trips classified as inshore benthic $(>75 \%)$ or offshore pelagic $(<75 \%)$ foraging

Regardless, an increase in foraging trip length over the chick-rearing period was evident in our data. This trend is congruent with an increase in foraging trip duration over chick-rearing in rockhopper (Tremblay \& Cherel 2005) and royal penguins (Hull et al. 1997). A foraging range expansion similar to the one we observed has also been recorded in Adelie penguins and attributed to changing energy demands of the chicks and adults, local food depletion and changes in sea ice extent (Ainley et al. 1998, Clarke et al. 2006). At Heard Island the absence of limitations to foraging imposed by sea ice suggests biotic factors are responsible for changes in foraging trip duration. Short trips performed during early guard stage are likely dictated by the need of very small chicks to be fed frequent meals and the requirement that one parent broods or guards the chick. It would be hard to envisage birds not taking advantage of a concentrated food source close to the colony if it was available. Therefore, the absence of inshore foraging late in the chick-rearing period suggests that either local depletion of resources due to intraspecific competition may be occurring (i.e. Ashmole's halo effect), or that there are temporal changes in prey distribution. It is also possible that foraging locations further from the colony are more reliable, or the high energy content of myctophid fish available is more profitable, making distant sites opti-
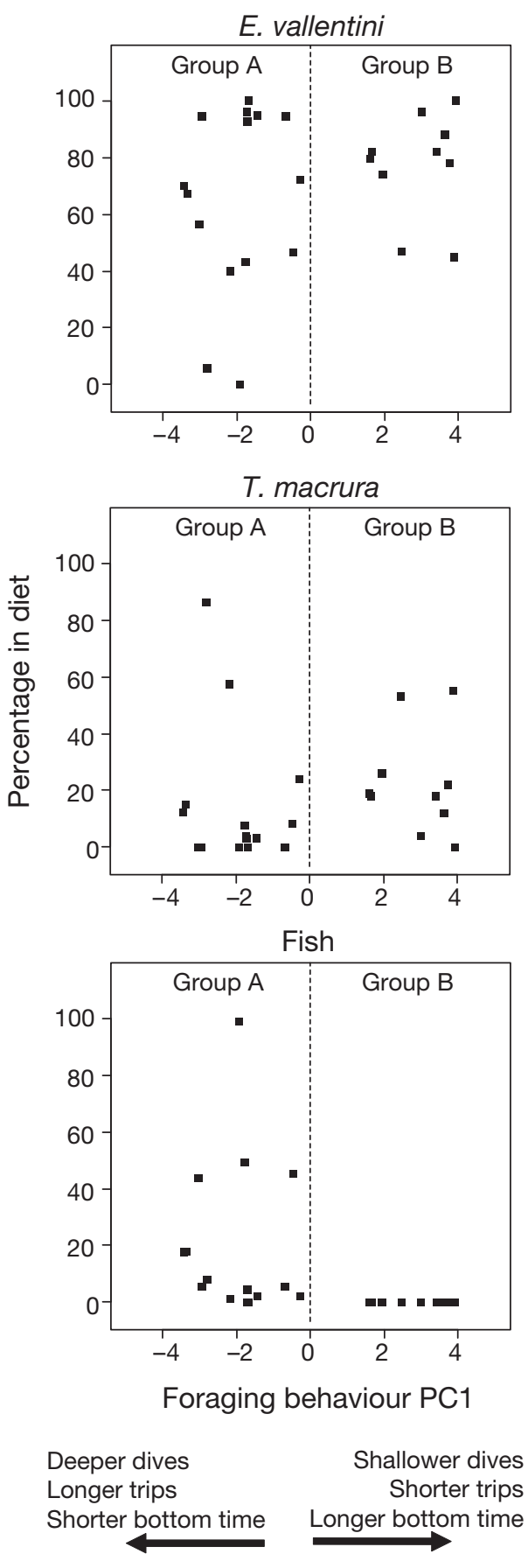

Fig. 9. Eudyptes chrysolophus. Relationship between a multivariate index of foraging behaviour and dietary composition of 25 early guard stage penguins. The 3 panels show PC1 from foraging parameters plotted against percent composition in the diet for each of the major prey species (see Fig. 1)

mal when time constraints and chick requirements have eased (see Alonzo et al. 2003 and discussion in Clarke et al. 2006). The occurrence of very long trips that were noticeable outliers occurred during the 
crèche stage in our study ( 2 trips that were $12 \mathrm{~d}$ ) and has also been reported during chick-rearing at South Georgia (trips up to 14 d; Barlow \& Croxall 2002a). These long trips presumably allow adults to replenish their own energy stores (Ainley et al. 1998) and in our study were carried out by male penguins after a period of fasting during chick guarding. The changes in trip characteristics we found between stages remain significant if we exclude data from male penguins.

\section{Foraging behaviour variation within the guard stage}

The analysis of individual variability in foraging behaviour over a short period at the beginning of guard stage revealed that 2 distinct types of foraging trips are utilized. One type involves birds taking foraging trips that lasted 1 or 2 days, extended roughly $50 \mathrm{~km}$ offshore from the colony and utilizing depths distributed broadly between 10 and $100 \mathrm{~m}$. These trips are typical of the pelagic foraging previously reported for guard stage macaroni penguins (Green et al. 1998, Barlow \& Croxall 2002a, Green et al. 2005). The other type of trip was a very short foray (range generally $<5 \mathrm{~km}$ ) in the neritic zone adjacent to the colony; the dives performed were shallow and characterised by long bottom times with rapid decent and ascent rates. The profile of dives carried out by birds on these inshore foraging trips matches those expected when prey is captured close to the sea floor (Tremblay \& Cherel 2000, Costa \& Gales 2003). During benthic foraging diving predators should maximise bottom time and minimise dive transit times, since time spent away from the bottom is unproductive (Costa \& Gales 2003). An alternative explanation for the long bottom times is that these are pelagic dives, but a higher proportion of dives involve prey capture which is occurring at the deepest part of the dive (Sato et al. 2004). In pelagic foraging, dives that are unsuccessful have longer decent and ascent rates, increasing search area by extending the horizontal distance covered and the possibility of moving into a prey patch in subsequent dives (Sato et al. 2004).

The integration of foraging location and dive data with bathymetry can provide unequivocal evidence of benthic dives (e.g. Rodary et al. 2000a, Ropert-Coudert et al. 2006). In the current study this was not directly possible since the resolution of the satellite telemetry data did not allow us to pinpoint the exact location of dives in an area where the bottom depth changes relatively quickly. However, the putative benthic dives occurred within an area were benthic dives were possible (i.e. close to the island in depths $<100 \mathrm{~m}$ ) and were not observed on trips into areas of deep water. Our IDZ analysis also indicates that during the short foraging trips, depths of successive dives were consistent. This observation further supports the proposition that the birds are carrying out benthic dives (Tremblay \& Cherel 2000, Takahashi et al. 2003). To our knowledge benthic dive behaviour has not been previously recorded in macaroni penguins, but the importance of this foraging strategy has been recognised in a wide range of other species of penguins including gentoo penguins Pygoscelis papua (Robinson \& Hindell 1996), rockhopper penguins Eudyptes chrysocome (Tremblay \& Cherel 2000), emperor penguins Aptenodytes forsteri (Rodary et al. 2000b), chinstrap penguins Pygoscelis antarctica (Takahashi et al. 2003), and little penguins Eudyptula minor (Ropert-Coudert et al. 2006). The variation in prey being targeted by these different species suggests that using the seabed to trap prey is a successful prey capture method for a range of prey types. Unlike individual-specific foraging patterns seen in some diving birds (Mehlum et al. 2001, Cook et al. 2006) birds in the current study that completed several foraging trips carrying data loggers showed no indication of focusing on a single foraging strategy (i.e. benthic versus pelagic) over successive trips. The foraging strategy adopted by macaroni penguins likely represents chance variation in prey patch detection: those birds which encounter prey close to shore while travelling in a trajectory away from the colony perform benthic dives and return to provision their chick; if no prey is encountered they continue offshore to forage (Trathan et al. 2006).

\section{Relationship between diet and foraging behaviour}

Direct links between the foraging patterns and the prey species captured by individual penguins have rarely been illustrated. This is due in part to the fact that the majority of foraging ecology studies focus on either behaviour or diet, with few carrying out a combined analysis on the same birds. In the current study, dietary analysis identified 3 main prey species: 2 euphausiids (Euphausia vallentini and Thysanoessa macrura) and a myctophid fish (Krefftichthys anderssoni). The main species of euphausiid consumed switched from E. vallentini in the early part of chickrearing to T. macrura later. When we compared foraging patterns of birds consuming the 2 euphausiids there were noticeable differences: E. vallentini was taken on trips that were shorter with shallower dives. However, these differences were correlated with changes in foraging behaviour that occurred over the study in all birds, so it is unclear whether they are a result of the prey consumed or an independent factor. Data from trawls carried out in early January 2003 at locations where the penguins foraged (over the plateau slope 
and deep water southeast of Heard Island) indicate both E. vallentini and T. macrura commonly co-occur in the upper $300 \mathrm{~m}$ of water and both species perform a diel vertical migration bringing them close to the surface at night (Australian Antarctic Division unpubl. data). The trawl data also show that during the day $E$. vallentini was only caught in trawls deeper than $100 \mathrm{~m}$ whereas $T$. macrura were caught in the upper 0 to $100 \mathrm{~m}$ zone. This observation is difficult to reconcile with the finding that diurnal penguins are foraging on $E$. vallentini in shallower dives compared with $T$. macrura. A possible explanation is offered by our tracking data: E. vallentini is primarily captured in shallow inshore water where its vertical migration is limited by the sea floor and T. macrura is more accessible offshore where deeper dives are performed. The possibility that E. vallentini aggregate near the bottom in neritic waters during the day making them targets for land based predators is discussed by Perissinotto \& McQuaid (1992). In addition, rockhopper penguins have been shown to forage on this species close to the sea floor in costal waters of the Kerguelen Archipelago (Tremblay \& Cherel 2000).

Our comparison of foraging parameters from birds that were feeding on euphausiids versus those that consumed a substantial amount of fish show the latter tended to travel further from the island and dive to greater depths. It was somewhat surprising that discernable differences were found given the large variability in foraging behaviour over the chick-rearing period and the fact that many of the birds consuming fish also captured significant numbers of euphausiids. The foraging differences we detected clearly indicate that the myctophid fish eaten by the penguins are not found in waters near the island. Fish remains (otoliths or tissue) were only recovered from birds returning from foraging trips that had a range of more than $30 \mathrm{~km}$ and only when the maximum dive depth attained during the trip was greater than $70 \mathrm{~m}$. None of the guard stage birds foraging inshore captured fish. This is not surprising given the dominance of the pelagic myctophid Krefftichthys anderssoni in the fish component of the diet of Heard Island macaroni penguins (Klages et al. 1989, Green et al. 1998, Deagle et al. 2007). A variety of other mesopelagic fish are present in the waters surrounding Heard Island, but most are found at depths below $100 \mathrm{~m}$ during the day (Duhamel et al. 2000, Australian Antarctic Division unpubl. data). Data from sampling conducted near Kerguelen (Duhamel et al. 2005) and Heard Island (Australian Antarctic Division unpubl. data) indicate $K$. anderssoni is exceptional in that its diel vertical migration brings it closer to the surface during the day (the opposite of other myctophid species in the area) making it the only myctophid with appreciable biomass accessible to macaroni penguins in the upper $100 \mathrm{~m}$ of water at this time.

The prey-related foraging parameters that we identified seem to reflect differences in prey distribution rather than prey-specific foraging tactics per se. Therefore, when the same species of prey are found in different habitat, large changes in foraging parameters can occur when the target species has not changed. This is clearly illustrated by birds with drastically different foraging patterns in early guard stage (i.e. inshore benthic dives versus offshore pelagic dives) that are capturing the same species of euphausiids. If predator behavioural data were recorded in more detail than in the present study it might be possible to detect preyspecific foraging tactics rather than habitat-specific patterns. For example, the accelerometers used by Ropert-Coudert et al. (2006) to monitor flipper beat frequency and body posture of little penguins, or the finescale undulations measured by Simeone \& Wilson (2003) may distinguish capture behaviours specific to different prey groups. The resolution of our analysis was also limited by the fact that the capture success of individual dives was unknown. This meant data from all dives and locations during a trip (including transit and unsuccessful searching activity) were compared to the stomach content data. If the foraging data could be filtered to include only the location and profiles of successful foraging dives it is likely more defined relationships between diet and foraging patterns would emerge.

In conclusion, this study highlights the variability of macaroni penguin foraging behaviour over the relatively short period of chick-rearing. This behavioural plasticity must be taken into consideration when generalising results from individual studies to make wider conclusions. Our analyses also show that changes in behavioural foraging parameters can signify dietary shifts; however, significant changes in behaviour do occur that are not associated with a change in diet. In the future, fine-scale behavioural measurements may uncover prey-specific foraging patterns, allowing behavioural data to be used to infer information about diet.

Acknowledgements. The authors thank the Heard Island expeditioners who helped in the study, especially K. Evans and R. Trebilco. We also thank P. Eveson, S. Frydman, S. Robinson and R. Trebilco for help collating the TDR and PTT datasets. R. Williams provided unpublished data from the Australian Antarctic Division on the distribution of prey species around Heard Island as well as useful discussion. Maps in Fig. 2 were produced by D. Smith from the Australian Antarctic Data Centre. The study was approved by the Australian Animal Ethics Committee (Department for the Environment and Heritage) and the University of Tasmania Animal Ethics Committee. The research was funded by the Australian Antarctic Division. 


\section{LITERATURE CITED}

Ainley DG, Wilson PR, Barton KJ, Ballard G, Nur N, Karl B (1998) Diet and foraging effort of Adelie penguins in relation to pack-ice conditions in the southern Ross Sea. Polar Biol 20:311-319

> Alonzo SH, Switzer PV, Mangel M (2003) Ecological games in space and time: the distribution and abundance of Antarctic krill and penguins. Ecology 84:1598-1607

Barlow KE, Croxall JP (2002a) Seasonal and interannual variation in foraging range and habitat of macaroni penguins Eudyptes chrysolophus at South Georgia. Mar Ecol Prog Ser 232:291-304

- Barlow KE, Croxall JP (2002b) Provisioning behaviour of macaroni penguins Eudyptes chrysolophus. Ibis 144:248-258

> Barlow KE, Boyd IL, Croxall JP, Reid K, Staniland IJ, Brierley AS (2002) Are penguins and seals in competition for Antarctic krill at South Georgia? Mar Biol 140:205-213

Boersma PD, Stokes DL, Stranger IJ (2002) Applying ecology to conservation: tracking breeding penguins at New Island South reserve, Falkland Islands. Aquat Conserv 12:63-74

Brooke M de L (2004) The food consumption of the world's seabirds. Proc R Soc Lond B 271:S246-S248

Brown CR, Klages NT (1987) Seasonal and annual variation in diets of macaroni (Eudyptes chrysolophus chrysolophus) and southern rockhopper (E. chrysocome chrysocome) penguins at sub-Antarctic Marion Island. J Zool 212:7-28

Charrassin JB, Le Maho Y, Bost CA (2002) Seasonal changes in the diving parameters of king penguins (Aptenodytes patagonicus). Mar Biol 141:581-589

Cherel Y, Hobson KA, Guinet C, Vanpe C (2007) Stable isotopes document seasonal changes in trophic niches and winter foraging individual specialization in diving predators from the Southern Ocean. J Anim Ecol 76:826-836

Clarke KR, Gorley RN (2001) PRIMER v5: User Manual/Tutorial. PRIMER-E, Plymouth

> Clarke J, Emmerson LM, Otahal P (2006) Environmental conditions and life history constraints determine foraging range in breeding Adélie penguins. Mar Ecol Prog Ser 310:247-261

> Cook TR, Cherel Y, Tremblay Y (2006) Foraging tactics of chick-rearing Crozet shags: individuals display repetitive activity and diving patterns over time. Polar Biol 29: 562-569

- Costa DP, Gales NJ (2003) Energetics of a benthic diver: seasonal foraging ecology of the Australian sea lion, Neophoca cinerea. Ecol Monogr 73:27-43

Crawford RJM, Cooper J, Dyer BM (2003) Population of the macaroni penguin Eudyptes chrysolophus at Marion Island, 1994/95-2002/03, with information on breeding and diet. Afr J Mar Sci 25:475-486

Croxall JP, Prince PA (1980) The food of gentoo penguins Pygoscelis papua and macaroni penguins Eudyptes chrysolophus at South Georgia. Ibis 122:245-253

Croxall JP, Prince PA, Baird A, Ward P (1985) The diet of the southern rockhopper penguin Eudyptes chrysocome chrysocome at Beauchêne Islands, Falkland Islands. J Zool 206:485-496

Croxall JP, Briggs DR, Kato A, Naito Y, Watanuki Y, Williams TD (1993) Diving pattern and performance in the macaroni penguin Eudyptes chrysolophus. J Zool 230:31-47

- Deagle BE, Gales NJ, Evans K, Jarman SN, Robinson S, Trebilco R, Hindell MA (2007) Studying seabird diet through genetic analysis of faeces: a case study on macaroni penguins (Eupyptes chrysolophus). PLoS ONE 2:e831

> Duhamel G, Koubbi P, Ravier C (2000) Day and night mesopelagic fish assemblages off the Kerguelen Islands (South- ern Ocean). Polar Biol 23:106-112

Duhamel G, Gasco N, Davaine P (2005) Poissons des Iles Kerguelen et Crozet: guide régional de l'Océan Austral, Vol 63. Muséum National d'Histoire Naturelle, Paris

- Frydman S, Gales NJ (2007) HeardMap: Tracking marine vertebrate populations in near real time. Deep-Sea Res 54: 384-391

Green K, Williams R, Green MG (1998) Foraging ecology and diving behaviour of macaroni penguins Eudyptes chrysolophus over the breeding season of 1992/93 at Heard Island. Mar Ornithol 26:27-34

Green JA, Boyd IL, Woakes AJ, Warren NL, Butler PJ (2005) Behavioural flexibility during year-round foraging in macaroni penguins. Mar Ecol Prog Ser 296:183-196

Harcourt RG, Bradshaw CJA, Dickson K, Davis LS (2002) Foraging ecology of a generalist predator, the female New Zealand fur seal. Mar Ecol Prog Ser 227:11-24

> Hull CL, Hindell MA, Michael K (1997) Foraging zones of royal penguins during the breeding season, and their association with oceanographic features. Mar Ecol Prog Ser 153:217-228

- Klages NTW, Gales RP, Pemberton D (1989) Dietary segregation of macaroni and rockhopper penguins at Heard Island. Aust Wildl Res 16:599-604

Lescroël A, Bost CA (2005) Foraging under contrasting oceanographic conditions: the gentoo penguin at Kerguelen Archipelago. Mar Ecol Prog Ser 302:245-261

Mehlum F, Watanuki Y, Takahashi A (2001) Diving behaviour and foraging habitats of Brunnich's guillemots (Uria lomvia) breeding in the high-Arctic. J Zool 255:413-423

Moore GJ, Wienecke B, Robertson G (1999) Seasonal change in foraging areas and dive depths of breeding king penguins at Heard Island. Polar Biol 21:376-384

> Perissinotto R, McQuaid CD (1992) Land-based predator impact on vertically migrating zooplankton and micronekton advected to a Southern Ocean archipelago. Mar Ecol Prog Ser 80:15-27

Robinson SA, Hindell MA (1996) Foraging ecology of gentoo penguins Pygoscelis papua at Macquarie Island during the period of chick care. Ibis 138:722-731

Rodary D, Bonneau W, Le Maho Y, Bost CA (2000a) Benthic diving in male emperor penguins Aptenodytes forsteri foraging in winter. Mar Ecol Prog Ser 207:171-181

- Rodary D, Wienecke BC, Bost CA (2000b) Diving behaviour of Adelie penguins (Pygoscelis adeliae) at Dumont D'Urville, Antarctica: nocturnal patterns of diving and rapid adaptations to changes in sea-ice condition. Polar Biol 23:113-120

Ropert-Coudert Y, Kato A, Bost CA, Rodary D, Sato K, Le Maho Y, Naito Y (2002) Do Adelie penguins modify their foraging behaviour in pursuit of different prey? Mar Biol 140:647-652

Ropert-Coudert Y, Kato A, Wilson RP, Cannell B (2006) Foraging strategies and prey encounter rate of free-ranging little penguins. Mar Biol 149:139-148

Ropert-Coudert Y, Wilson RP, Yoda K, Kato A (2007) Assessing performance constraints in penguins with externallyattached devices. Mar Ecol Prog Ser 333:281-289

Ruxton GD (2006) The unequal variance $t$-test is an underused alternative to Student's $t$-test and the Mann-Whitney $U$-test. Behav Ecol 17:688-690

Sato K, Charrassin JB, Bost CA, Naito Y (2004) Why do macaroni penguins choose shallow body angles that result in longer descent and ascent durations? J Exp Biol 207: 4057-4065

Simeone A, Wilson RP (2003) In-depth studies of Magellanic penguin (Spheniscus magellanicus) foraging: Can we esti- 
mate prey consumption by perturbations in the dive profile? Mar Biol 143:825-831

Takahashi A, Dunn MJ, Trathan PN, Sato K, Naito Y, Croxall JP (2003) Foraging strategies of chinstrap penguins at Signy Island, Antarctica: importance of benthic feeding on Antarctic krill. Mar Ecol Prog Ser 250:279-289

Trathan PN, Green C, Tanton J, Peat H, Poncet J, Morton A (2006) Foraging dynamics of macaroni penguins Eudyptes chrysolophus at South Georgia during brood-guard. Mar Ecol Prog Ser 323:239-251

Trebilco R (2004) Macaroni penguin (Eudyptes chrysolophus) foraging ecology at Heard Island: behaviour and environmental influences. Honours Thesis, University of Tasmania, Hobart

Tremblay Y, Cherel Y (2000) Benthic and pelagic dives: a new foraging behaviour in rockhopper penguins. Mar Ecol Prog Ser 204:257-267

Tremblay Y, Cherel Y (2003) Geographic variation in the foraging behaviour, diet and chick growth of rockhopper penguins. Mar Ecol Prog Ser 251:279-297

Tremblay Y, Cherel Y (2005) Spatial and temporal variation in the provisioning behaviour of female rockhopper penguins Eudyptes chrysocome filholi. J Avian Biol 36:135-145

Editorial responsibility: Rory Wilson,

Swansea, UK
Walker BG, Boersma PD (2003) Diving behaviour of Magellanic penguins (Spheniscus megellanicus) at Punta Tombo, Argentina. Can J Zool 81:1471-1483

Wienecke B, Robertson G (2002) Foraging areas of king penguins from Macquarie Island in relation to a marine protected area. Environ Manage 29:662-672

Wilson RP (1984) An improved stomach pump for penguins and other seabirds. J Field Ornithol 55:109-112

Wilson RP, Pütz K, Charrassin JB, Lage J (1995) Artifacts arising from sampling interval in dive depth studies of marine endotherms. Polar Biol 15:575-581

Wilson RP, Grémillet D, Syder J, Kierspel MAM and others (2002) Remote-sensing systems and seabirds: their use, abuse and potential for measuring marine environmental variables. Mar Ecol Prog Ser 228:241-261

Woehler EJ (1995) Bill morphology of royal and macaroni penguins and geographic variation within eudyptid penguins. In: Dann P, Norman I, Reillly P (eds) The penguins. Surrey Beatty \& Sons, Chipping Norton, p 319-330

Woehler EJ (2006) Status and conservation of the seabirds of Heard Island. In: Green K, Woehler EJ (eds) Heard Island: Southern Ocean sentinel. Surrey Beatty \& Sons, Chipping Norton, p 128-165

Submitted: February 14, 2007; Accepted: October 29, 2007 Proofs received from author(s): April 3, 2008 